\title{
Mixed Nickel-Cobalt-Molybdenum Metal Oxide Nanosheet Arrays for Hybrid Supercapacitor Applications
}

\author{
Yin She ${ }^{1,2}$, Bin Tang ${ }^{3}$, Dongling $\mathrm{Li}^{1,2}{ }^{1,}$ Xiaosheng Tang ${ }^{1,2}$, Jing Qiu ${ }^{1}$, Zhengguo Shang ${ }^{1,2}$ and \\ Wei $\mathrm{Hu}^{1, *}$ \\ 1 Key Laboratory of Optoelectronic Technology and System of Ministry of Education, \\ College of Optoelectronic Engineering, Chongqing University, Chongqing 400044, China; \\ sheyin@cqu.edu.cn (Y.S.); lidongling@cqu.edu.cn (D.L.); xstang@cqu.edu.cn (X.T.); \\ jingqiu@cqu.edu.cn (J.Q.); zhengry@cqu.edu.cn (Z.S.) \\ 2 Key Laboratory of Fundamental Science Micro/Nano Device System Technology, Micro System Research \\ Center of Chongqing University, Chongqing 400044, China \\ 3 Institute of Electronic Engineering, China Academy of Engineering Physics, Mianyang 621999, China; \\ tangbin@caep.cn \\ * Correspondence: weihu@cqu.edu.cn; Tel.: +86-138-9611-1800
}

Received: 16 July 2018; Accepted: 19 September 2018; Published: 25 September 2018

\begin{abstract}
Mixed metal oxide nanomaterials have been demonstrated to be promising positive electrodes for energy storage applications because of the synergistic enhancement effects. In this work, nickel-cobalt-molybdenum metal oxide (NCMO) nanosheets with hierarchical, porous structures were directly developed on nickel foam (NF) through a hydrothermal method and ensuing annealing treatment. Electrochemical tests in three-electrode configurations revealed that the as-prepared NCMO nanosheets possessed high specific capacitance $\left(1366 \mathrm{~F} \mathrm{~g}^{-1}\right.$ at the current density of $\left.2 \mathrm{~A} \mathrm{~g}^{-1}\right)$, good rate capability $\left(71.3 \%\right.$ at the current density of $\left.40 \mathrm{~A} \mathrm{~g}^{-1}\right)$, as well as excellent cycling stability (89.75\% retention after 5000 cycles). Additionally, a hybrid supercapacitor was assembled and achieved an energy density of $46.2 \mathrm{Wh} \mathrm{kg}^{-1}$ at a power density of $713 \mathrm{~W} \mathrm{~kg}^{-1}$. Based on the systematic analysis of microstructure, morphology, and element compositions, the excellent electrochemical performance of the NCMO nanosheets could be attributed to the mesoporous feature, desirable compositions, excellent mechanical and electrical contacts, and fast ion/electron transportation rates. This study shows that the NCMO nanosheets offer great potentials for application in supercapacitors.
\end{abstract}

Keywords: mixed metal oxides; nanosheet arrays; nickel-cobalt-molybdenum metal oxide (NCMO); supercapacitor; energy storage

\section{Introduction}

High performance and environmentally friendly electrochemical energy storage devices and systems have received widespread attention because of the huge demands for clean, efficient, and sustainable energy in recent decades [1-4]. Among the myriad available power sources, supercapacitors, with complementary characteristics of lithium-ion batteries and electrostatic capacitors, have sparked a dramatic expansion of academic research and industrial interests [5-7]. Especially, hybrid supercapacitors, consisting of a pseudocapacitor electrode and an electric double layer capacitor electrode, have aroused more and more attention since they possess the merits of both types of electrodes and display average properties of battery-level energy density and high power density, long cycling stability, and short charging time of conventional capacitors [8-11]. 
It is well acknowledged that a pseudocapacitor electrode plays a key role in achieving high-performance hybrid supercapacitors, which mainly collect the charges from the Faradic reactions that have occurred on the electrode surface. Thus, considerable efforts have been devoted to developing pseudocapacitor electrode materials that undergo abundant redox reactions [12-14]. Given the properties of richer reaction sites, higher electrochemical activities and electronic conductivities compared with the corresponding binary oxides, sulfides, and hydroxides, ternary metal oxides along with ternary metal sulfides and hydroxides have been widely explored [15-20]. For instance, Guan and co-workers fabricated Co-Mn double hydroxides by an electro-deposition, which showed capacitance of $1062.6 \mathrm{~F} \mathrm{~g}^{-1}$ at $0.7 \mathrm{~A} \mathrm{~g}^{-1}$ and cyclability of $96.3 \%$ after 5000 cycles [21]. Luo's group synthesized mesoporous $\mathrm{CuCo}_{2} \mathrm{O}_{4}$ nano-grasses on copper foam, showing a specific capacitance of $796 \mathrm{~F} \mathrm{~g}^{-1}$ at $2 \mathrm{~A} \mathrm{~g}^{-1}$ and a cyclic stability of $94.7 \%$ after 5000 cycles [22]. Rout et al. developed nickel cobalt sulfide ultrathin nanosheets by electro-deposition method. When used as the pseudo-electrodes, the prepared nickel-cobalt sulfide nanosheets displayed capacitances of $1712 \mathrm{~F} \mathrm{~g}^{-1}$ at $1 \mathrm{~A} \mathrm{~g}^{-1}$ and retained $87 \%$ after 3000 cycles [23]. The previous studies indicated that the ternary metal sulfide electrodes displayed outstanding specific capacitance, but suffered from poor cycling stability. While the ternary metal oxides and hydroxides electrodes displayed high cycling stability, the specific capacitances were comparatively low because of their poor intrinsic charge/ionic conductivity and the diffusion-controlled process limitation.

More recently, mixed metal oxides, composed of three or more metal elements with similar radii, are expected to have a stronger synergetic effect in comparison with the corresponding binary and ternary metal oxides [24-26]. Tu's group synthesized spinel Mn-Ni-Co ternary oxide nanowires on nickel foam (NF) for supercapacitor application, which showed high specific capacitance together with good cyclability [27]. Lee et al. fabricated Ni-Co-Mn metal oxide nanoparticles on reduced graphene oxide and intensively studied the high capacitance mechanism of the mixed metal oxide [28]. In our previous work, we have synthesized Ni-Zn-Co oxide nanowire arrays through a hydrothermal reaction, which showed high capacitance and long-term cycling stability [29].

By taking advantage of the synergetic effect to improve electrochemical activity and stability, it is of great significance to explore and achieve high-performance pseudocapacitor electrodes in mixed metal oxide nanostructures. Though ternary $\mathrm{CoMoO}_{4}$ and $\mathrm{NiMoO}_{4}$ nanomaterials and heterostructures have been intensively investigated, there are few reports on mixed nickel-cobalt-molybdenum metal oxide (NCMO) for supercapacitor applications. Herein, we present a facile synthesis of mixed NCMO nanosheets on NF through the combination of a hydrothermal method and ensuing annealing treatment. The NCMO nanosheets manifested exceptional electrochemical performances, including high specific capacitance and good cycling stability, owing to the following features: (1) the ultrathin nanosheets structure and mesoporous morphology provided large specific surface area and in turn enlarge the utilization of the electrode materials and further facilitate the irrigation of electrolyte, prompting Faradic redox reactions; (2) the molybdenum element showed intercalation pseudocapacitive behaviour through reversible intercalation/deintercalation; (3) the poor crystallization resulted in an increase in defect transportations in NCMO nanosheets compared to a material with good crystallinity; (4) moreover, the mesopores on the nanosheets served as "ion-buffering reservoirs" and brought about short effective diffusion paths [30-33]. In a word, the NCMO nanosheets are expected to act as high-performance pseudocapacitor electrode materials for hybrid supercapacitor applications.

\section{Materials and Methods}

\subsection{Materials Preparation}

Firstly, $1 \mathrm{mmol} \mathrm{Ni}\left(\mathrm{NO}_{3}\right)_{2} \cdot 6 \mathrm{H}_{2} \mathrm{O}, 1 \mathrm{mmol} \mathrm{Co}\left(\mathrm{NO}_{3}\right)_{2} \cdot 6 \mathrm{H}_{2} \mathrm{O}, 1 \mathrm{mmol} \mathrm{Na} \mathrm{MoO}_{4} \cdot 2 \mathrm{H}_{2} \mathrm{O}, 6 \mathrm{mmol}$ $\mathrm{NH}_{4} \mathrm{~F}$ together with $15 \mathrm{mmol} \mathrm{CO}\left(\mathrm{NH}_{2}\right)_{2}$ were simultaneously dissolved in $70 \mathrm{~mL}$ deionized (DI) water and stirred for $1 \mathrm{~h}$ under room temperature. After then, we transformed the forming solution into a 
$100 \mathrm{~mL}$ Teflon-lined stainless steel autoclave with a rectangular NF $(3 \mathrm{~cm} \times 5 \mathrm{~cm})$ immersed in it. It is worth noting that a sheet of polytetrafluoroethylene tape was adhered onto the top side of the NF in order to avoid the solution invasion. Subsequently, we kept the sealed autoclave in an oven at $120^{\circ} \mathrm{C}$ for $5 \mathrm{~h}$. After the autoclave cooled down to room temperature, we obtained the $\mathrm{Ni}$-Co-Mo precursor and washed it by DI water and ethanol for many times, followed by drying at $80^{\circ} \mathrm{C}$ for $6 \mathrm{~h}$. Finally, an annealing treatment was conducted under conditions of $350{ }^{\circ} \mathrm{C}$ for $2 \mathrm{~h}$ in an air atmosphere with a ramp rate of $2{ }^{\circ} \mathrm{C} \mathrm{min}^{-1}$. The mass loading of the active materials on NF was about $1.2 \mathrm{mg} \mathrm{cm}^{-2}$.

\subsection{Hybrid Supercapacitor Fabrication}

A hybrid supercapacitor was composed of NCMO nanosheets as the positive electrode and the activated carbon (AC) mixture as the negative electrode. The negative electrode was fabricated by the following two steps: (1) Initially, a mixture consisting of activated carbon, acetylene black, and polyvinylidene fluoride with a mass ratio of 8:1:1 was poured into the $N$-methyl-2-pyrrolidone solvent to form a slurry; (2) then we coated the slurry on a rectangular shaped NF and dried at $80^{\circ} \mathrm{C}$ for $12 \mathrm{~h}$. Based on the charge balance theory, the mass balancing of both negative and positive electrodes can be optimized as the relationship: $\frac{m_{+}}{m_{-}}=\frac{C_{-} \times \Delta E_{-}}{C_{+} \times \Delta E_{+}}$, where $C_{+}$and $C_{-}$stand for the specific capacitances of the positive and negative electrodes, respectively. $\Delta E$ is the potential range [34-37].

\subsection{Materials Characterization}

An X-ray diffractometer (XRD; RIGAKU D-MAX 2200; $\mathrm{Cu}$ K $\alpha$ radiation, Tokyo, Japan) was utilized to characterize the crystal phases. Scanning electron microscopy (SEM; QUANTA 400F, Thermo Fisher Scientific, Waltham, MA, USA) and transmission electron microscopy (TEM; JEOL JEM-2010HR, JEOL Ltd., Tokyo, Japan) were performed to check the structures and morphologies. X-ray photoelectron spectroscopy (XPS; ESCALAB 250, Al K $\alpha$ radiation, Thermo Fisher Scientific, Waltham, MA, USA) was applied to investigate the chemical states. A surface area analyzer (Micromeritics ASAP 2020, Norcross, GA, USA) was employed to investigate the surface characteristics via nitrogen adsorption/desorption measurements.

\subsection{Measurements of Electrochemical Performance}

The electrochemical measurements were implemented by a three-electrode electrochemical setup. The as-fabricated $\mathrm{Ni}-\mathrm{Co}-\mathrm{Mo}$ oxide nanosheet arrays, a platinum foil, a saturated calomel electrode (SCE), and 2.0 M KOH solution were applied as the working electrode, the counter electrode, the reference electrode, and the electrolyte, respectively. Cyclic voltammetry (CV) and galvanostatic charge/discharge (GCD) tests, electrochemical impedance spectroscopy (EIS), and cycling characteristics were performed on an electrochemical workstation (CHI 660E, Chenhua Instrument, Shanghai, China). The specific capacitance $\left(\mathrm{F} \mathrm{g}^{-1}\right)$, areal capacitance $\left(\mathrm{F} \mathrm{cm}^{-2}\right)$, energy density $\left(\mathrm{Wh} \mathrm{kg}^{-1}\right)$, and power density $\left(\mathrm{W} \mathrm{kg}^{-1}\right)$ could be calculated from the galvanostatic discharge curves in light of the following equation: $C_{s}=\frac{I \times \Delta t}{V \times m} ; C_{a}=\frac{I \times \Delta t}{V \times S} ; E=\frac{1}{2} \times C_{s} \times V^{2} ; P=E / \Delta t$, where $I$, $\Delta t, m, V$, and $S$ are designated as the discharge current and time, the mass, the potential window, and the area of active electrode, respectively [35].

\section{Results and Discussion}

\subsection{Structure and Morphology Characterizations}

The crystal structure of the obtained product scratched from NF was examined by XRD, and the corresponding pattern is shown in Figure 1. The observed diffraction peaks at the degrees of 36.6 and 62.9 could be indexed to the (202) and (260) planes of the cubic phase of $\mathrm{NiMoO}_{4}$ (JCPDF card No. 45-0142), and the other diffraction peaks can be indexed to $\mathrm{CoMoO}_{4}$ (JCPDF card No. 21-0868) [36,37]. Moreover, the peak intensities are relatively weak and broad, which indicates the poor crystallization of the NCMO nanosheets. The poor crystallization is beneficial for increased electrochemical performance 
because more defect transportations are present in materials with weak crystallinity [38]. It is also worth noting that, differing from the previous reported Ni-Co-Mn oxides, Ni-Co-Zn oxides, and other mixed metal oxide nanostructures prepared by a similar hydrothermal method, the hydrothermal processed NCMO nanosheets do not show the spinel structure. It could be caused by the substitution of Mo, which affected the spinel crystal structure significantly $[26,27,39]$.

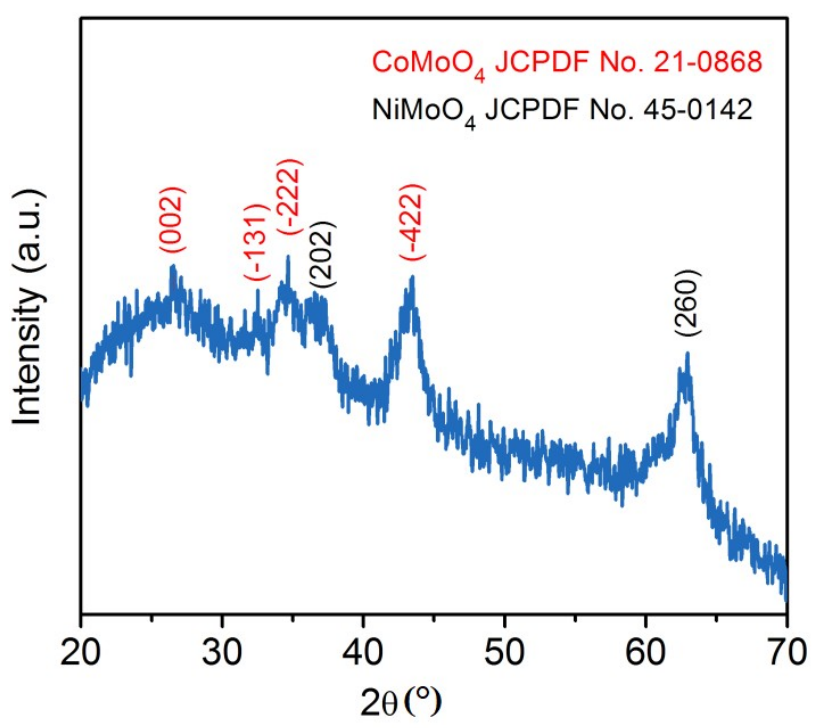

Figure 1. X-ray diffraction (XRD) pattern of the nickel-cobalt-molybdenum metal oxide (NCMO) nanosheets sample.

From the SEM images in Figure 2a-c, it can be seen that the crinkly NCMO nanosheets are uniformly and continuously deposited on NF. The NCMO nanosheets interlace with each other to arrange vertically on the substrate, forming an open-up network structure. The average thickness of the nanosheets is approximately $40 \mathrm{~nm}$. The corresponding elemental mapping images, including $\mathrm{Ni}$, $\mathrm{Co}, \mathrm{Mo}$, and $\mathrm{O}$ elements, have been separately listed in Figure $2 \mathrm{~d}$ and indicate the uniform dispersion of all the elements. Further insight into the detailed microstructure was elucidated by TEM. Figure 2e,f shows the low- and high-resolution TEM images of NCMO nanosheets. The surface of the NCMO nanosheets is continuous and relatively thin with a porous architecture, which could be ascribed to the successive release and loss of the produced gas during thermal reactions [40-42]. The thin and mesoporous characteristics of the nanosheets may provide a large surface area and more electroactive sites for Faradaic reactions, facilitating charge transfer between the electrode interface and electrolyte. The high-resolution TEM image of Figure $2 \mathrm{f}$ demonstrated the polycrystalline characteristics.

XPS measurements were carried out to further confirm the element compositions and the chemical states of the NCMO nanosheets. The corresponding experimental and fitted spectra are presented in Figure 3. As shown in Figure 3a, peaks of Ni, Co, Mo, and $\mathrm{O}$ elements are visualized. The deconvolutions of Ni 2p, Mo 2p, Co 2p, and O 1s are presented in Figure 3b-e, respectively. As indicated in Figure 3b, the Ni 2p XPS spectrum presents two spin-orbit doublets and two satellites. $\mathrm{Ni} 2 \mathrm{p}_{1 / 2}$ and $\mathrm{Ni} 2 \mathrm{p}_{3 / 2}$ spin-orbit peaks are located at 873.4 and $856.1 \mathrm{eV}$, respectively, with a splitting energy of $17.3 \mathrm{eV}$, implying the existence of the $\mathrm{Ni}^{2+}$ oxidation state in the nanosheet arrays [42]. The Co $2 p$ region can be best fitted into two prominent peaks in Figure $3 \mathrm{c}$ with the binding energies at 786.3 and $804.2 \mathrm{eV}$, corresponding to the $\mathrm{Co} 2 \mathrm{p}_{1 / 2}$ and $\mathrm{Co} 2 \mathrm{p}_{3 / 2}$ levels, which is a signature of $\mathrm{Co}^{2+}$ and $\mathrm{Co}^{3+}$ oxidation states [43]. In Figure $3 \mathrm{~d}$, the peaks at 235.3 and $232.3 \mathrm{eV}$ are ascribed to $\mathrm{Mo}^{3} \mathrm{~d}_{3 / 2}$ and Mo $3 d_{5 / 2}$ levels, respectively [44]. The spin-orbit splitting value of Mo $3 d_{3 / 2}$ and Mo $3 d_{5 / 2}$ is $2.0 \mathrm{eV}$, which signifies the $\mathrm{Mo}^{6+}$ oxidation state in NCMO nanosheets. The fitted peaks of the O $1 \mathrm{~s}$ XPS spectrum in Figure 3e centered at 531.5 and $532.8 \mathrm{eV}$. The main peak at $531.5 \mathrm{eV}$ confirms the formation 
$\mathrm{M}-\mathrm{O}(\mathrm{M}=\mathrm{Co}, \mathrm{Ni}, \mathrm{Mo})$ bonds and the dwarf peak at $532.8 \mathrm{eV}$ may be associated with the deficient oxygen or the surface-absorbed oxygen species in NCMO nanosheets [45].

(a)

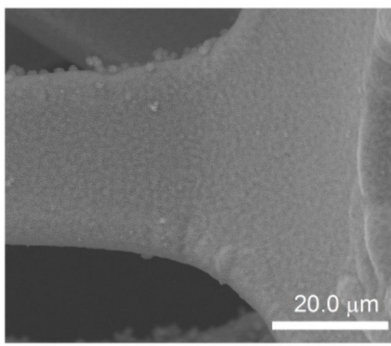

(d)

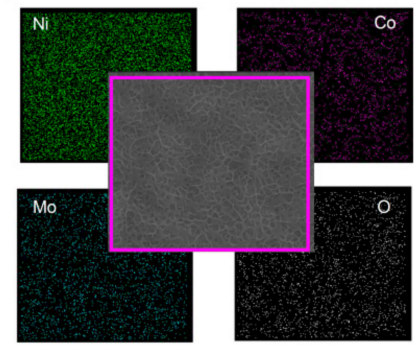

(b)

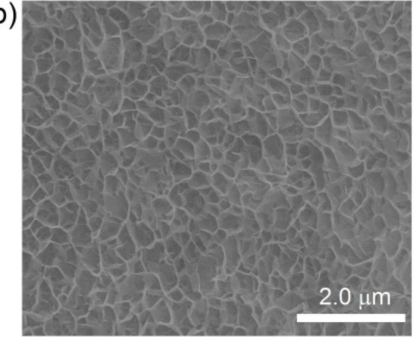

(e)

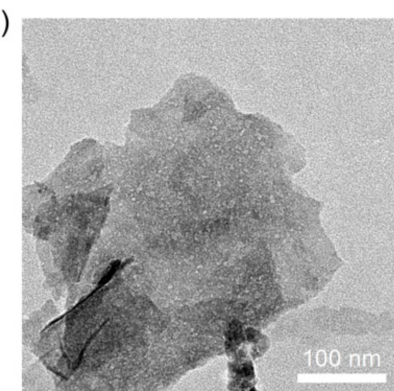

(c)

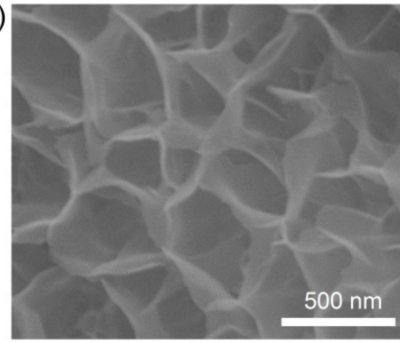

(f)

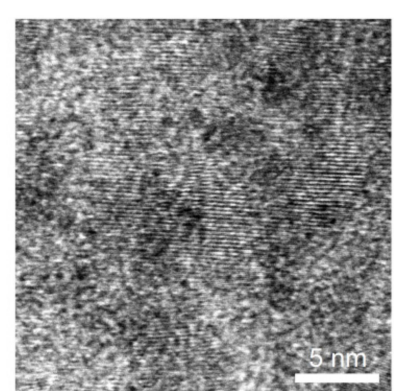

Figure 2. Morphology and microstructure characterizations. (a-c) Scanning electron microscopy (SEM) images of the NCMO nanosheets on nickel foam (NF) with different magnifications. (d) Elemental mappings of $\mathrm{Ni}, \mathrm{Co}, \mathrm{Mo}$, and $\mathrm{O}$ atoms of the NCMO nanosheets. (e,f) Transmission electron microscopy (TEM) images of the NCMO nanosheets sample.
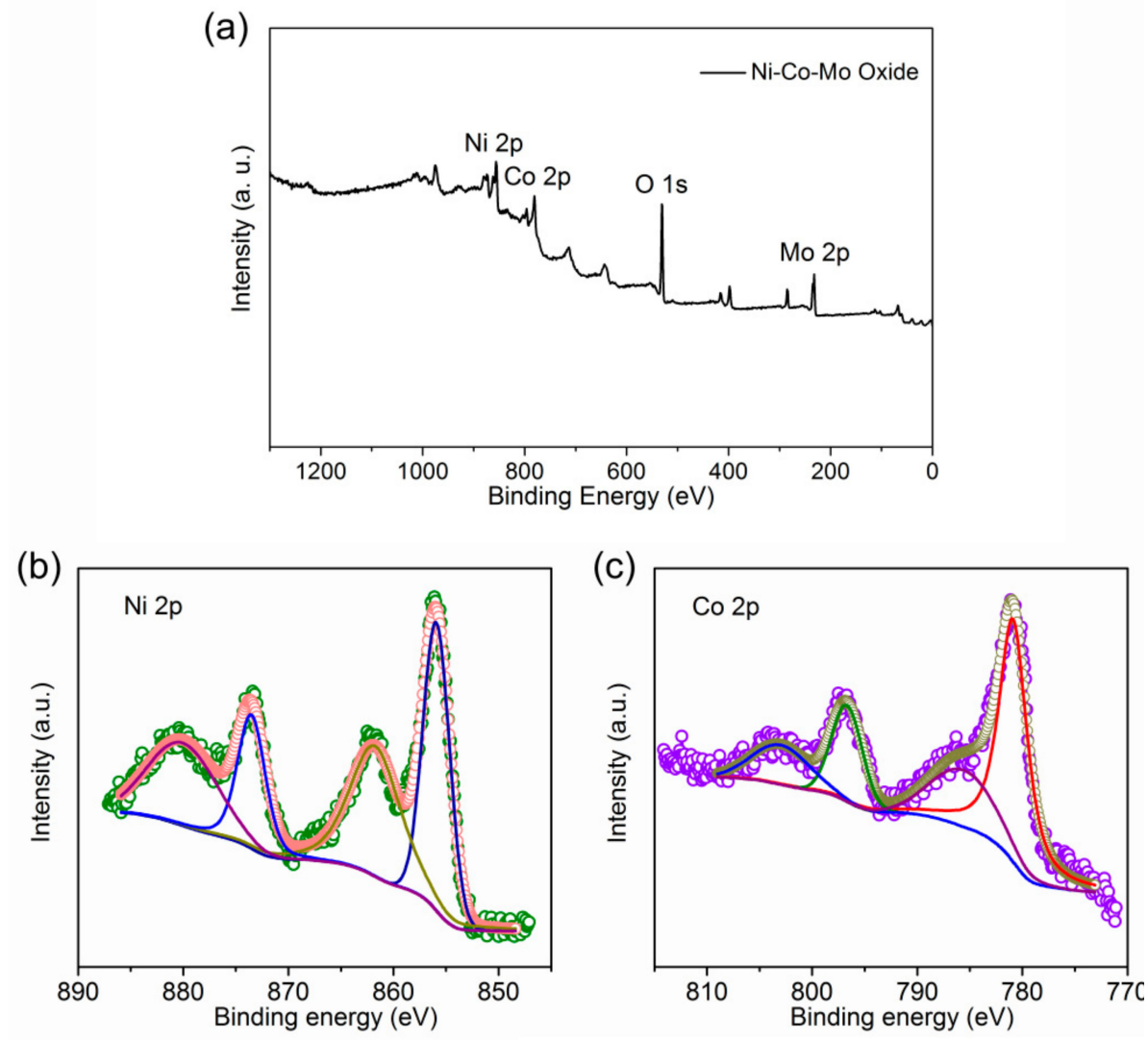

Figure 3. Cont. 

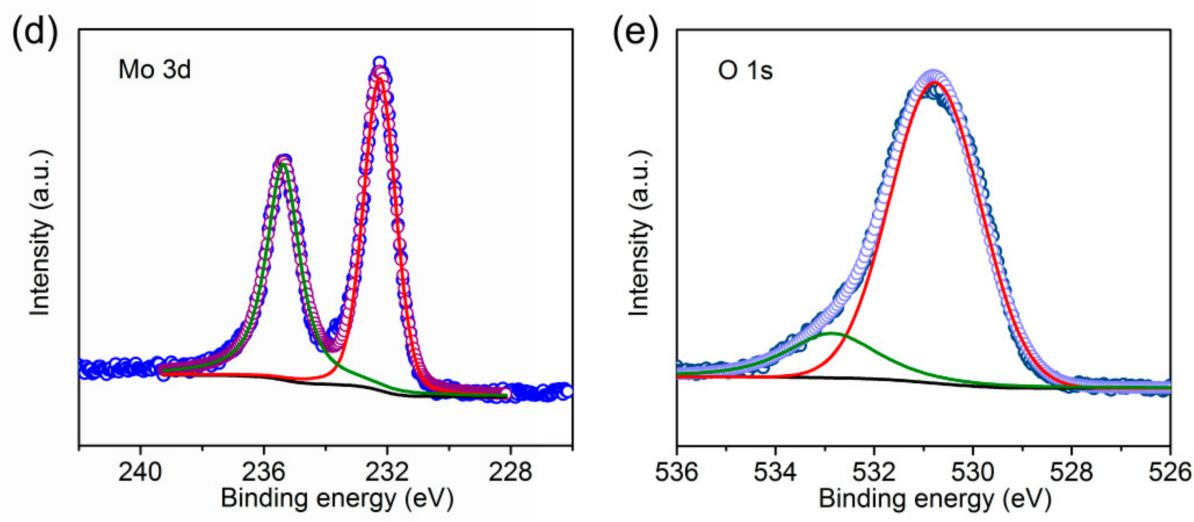

Figure 3. (a) X-ray photoelectron spectroscopy (XPS) survey spectrum of NCMO nanosheets. High-resolution XPS spectra of (b) Ni 2p, (c) Co 2p, (d) Mo 3d, and (e) O 1s of the NCMO nanosheets sample.

Figure 4 shows the nitrogen adsorption/desorption isotherms and the corresponding pore size distribution plot of the Ni-Co-Mo oxide nanosheet arrays. Notably, Figure 4a displays a distinct hysteresis loop, indicating the mesoporous characteristics. The Ni-Co-Mo oxide nanosheet arrays exhibited a high Brunauer-Emmett-Teller (BET) specific surface area of $94.4 \mathrm{~m}^{2} \mathrm{~g}^{-1}$ and the corresponding pore size distribution curve scattered within the range from 2 to $10 \mathrm{~nm}$, as shown in Figure $4 \mathrm{~b}$. The high surface area and mesoporous structures will facilitate the redox reaction between the electrolyte ions and $\mathrm{Ni}-\mathrm{Co}-\mathrm{Mo}$ oxide electrode not only by affording sufficient reaction sites and large surface for the electrolyte to permeate but also by accelerating ion diffusion and electron transportation.
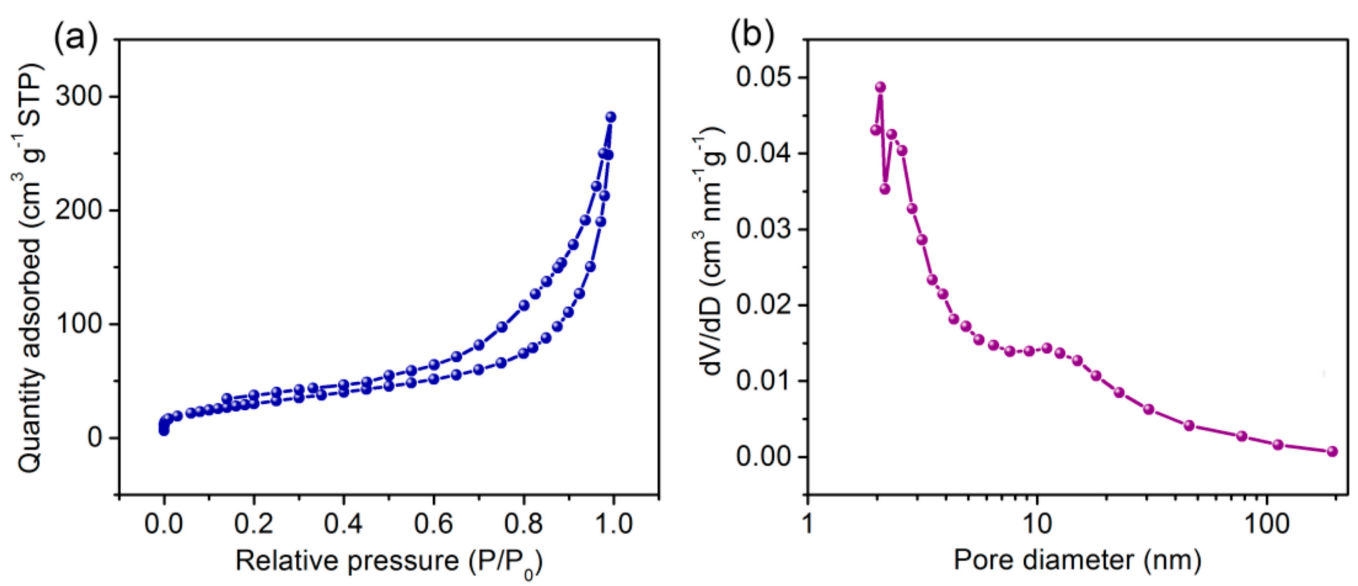

Figure 4. (a) Nitrogen (77 K) adsorption/desorption isotherms and (b) the corresponding pore size distribution profile of the NCMO nanosheets.

\subsection{Electrochemical Properties}

Enlightened by the advantageous structural features and compositional merits, the electrochemical properties of the as-fabricated NCMO nanosheets on NF were appraised by CV and GCD measurements. Figure 5a illustrates the typical $C V$ curves with a 0 to $0.6 \mathrm{~V}$ potential range from 5 to $30 \mathrm{mV} \mathrm{s}^{-1}$. Clearly, the $\mathrm{CV}$ curves manifest a pair of distinct redox peaks during the cathodic and anodic sweepings, which are governed by Faradaic reversible reactions mainly related to $\mathrm{M}-\mathrm{O} / \mathrm{M}-\mathrm{O}-\mathrm{OH}$ reactions (M represents $\mathrm{Ni}$ or $\mathrm{Co}$ ). In other words, the electrochemical capacitance of NCMO is attributed to the quasi-reversible electron transfer process that mainly involves the $\mathrm{Ni}^{2+} / \mathrm{Ni}^{3+}$ and $\mathrm{Co}^{2+} / \mathrm{Co}^{3+}$ redox couples, and is probably mediated by the $\mathrm{OH}^{-}$ions in the alkaline electrolyte. In fact, 
the Mo atoms do not participate in any redox reaction; the redox behavior of Mo has no contribution to the measured capacitance. Even though the Mo element did not participate in the Faraday reaction, the introduction of Mo affected the crystal structure. Additionally, the molybdenum oxide showed intercalation pseudocapacitive behavior through reversible intercalation/deintercalation of $\mathrm{K}^{+}$ions into/out of the nanostructures [46,47]. Moreover, when the scan rate increases from 5 to $30 \mathrm{mV} \mathrm{s}^{-1}$, the profiles of the $\mathrm{CV}$ curves are well maintained and the oxidation peak shifts moderately from 0.39 to $0.54 \mathrm{~V}$. This observation implies good electronic conductivity, outstanding electrochemical reversibility, and fast ion/electron transfer kinetics during Faradaic reactions. Figure 5b depicts the GCD curves at the current densities from 2 to $40 \mathrm{~A} \mathrm{~g}^{-1}$. The GCD curves are approximately symmetrical and display a distinct plateau region at charge/discharge processes with no obvious internal ohmic (iR) drop, which suggests Faradaic reactions with low internal resistance [48].

The specific and areal capacitances calculated from the GCD plots are pictured in Figure $5 \mathrm{c}, \mathrm{d}$, respectively. The specific capacitances are as high as 1366, 1340,1323, 1298, 1277, 1156, 1066, and $973 \mathrm{~F} \mathrm{~g}^{-1}$ and the areal capacitances are 1.64, 1.61, 1.59, 1.56, 1.53, 1.39, 1.28, and $1.17 \mathrm{~F} \mathrm{~cm}^{-2}$ at current densities from 2 to $40 \mathrm{~A} \mathrm{~g}^{-1}$, respectively [35]. Moreover, the NCMO nanosheets hold $71.3 \%$ retention of the capacitance, revealing the good rate capability and diffusion limitation effect [16]. The cycling stability measured by the repetitive charge and discharge processes at the current density of $30 \mathrm{~A} \mathrm{~g}^{-1}$ was depicted in Figure 5e. Impressively, the specific capacitance had a retention of $89.75 \%$ even after 5000 cycles.
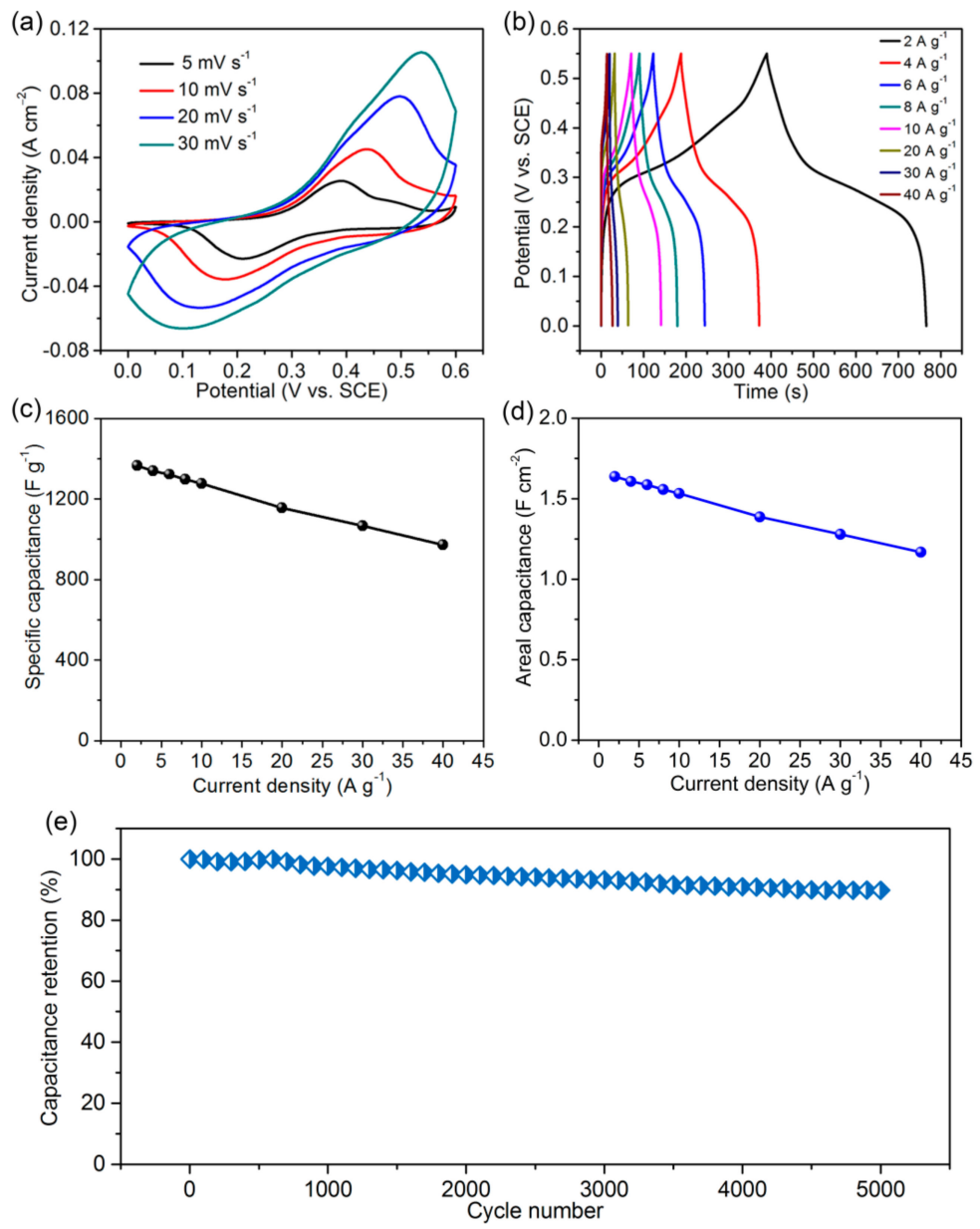

Figure 5. (a) Cyclic voltammetry (CV) properties of NCMO sample at various scan rates. (b) Galvanostatic charge/discharge (GCD) measurements at different current densities. (c,d) The specific capacitances and areal capacitances calculated from the GCD plots. (e) Long-term cycling manifestation at a current density of $30 \mathrm{~A} \mathrm{~g}^{-1}$. 
With the aim to assess the potential energy storage applications of the NCMO nanosheets, a hybrid supercapacitor was assembled. The CV plots shown in Figure 6a were performed at various sweep rates from 5 to $50 \mathrm{mV} \mathrm{s}^{-1}$ in a potential range from 0 to $1.8 \mathrm{~V}$. It was observed that all the curves behave similarly in shape with a conspicuous pair of redox peaks. The wide potential window is beneficial for promoting the energy density. With the increase of the scan rates, the CV curves displayed very slight shifts of the redox peaks, indicating the device possesses outstanding rate capability. Figure $6 \mathrm{~b}$ illustrates GCD results of the hybrid supercapacitor cell. The nearly symmetrical shape of the curves announces the superior reversibility of Faradaic reactions and good electrochemical capacitive characteristics [49]. Figure $6 \mathrm{c}$ records the Nyquist impedance spectrum of the hybrid supercapacitor. The semicircle region of the spectrum demonstrated that the charge transfer resistance was about $1.0 \Omega$, implying good charge-transfer kinetics and fast electron transport [50]. The Ragone plots correlated containing/covering the energy density with the power density of the hybrid supercapacitor cell were depicted in Figure 6d. These plots revealed that the device manifested a high energy density of $46.2 \mathrm{Wh} \mathrm{kg}^{-1}$ at $713.0 \mathrm{~W} \mathrm{~kg}^{-1}$, which remained a high energy density of $38.0 \mathrm{Wh} \mathrm{kg}^{-1}$ at $7130 \mathrm{~W} \mathrm{~kg}^{-1}$.

(a)

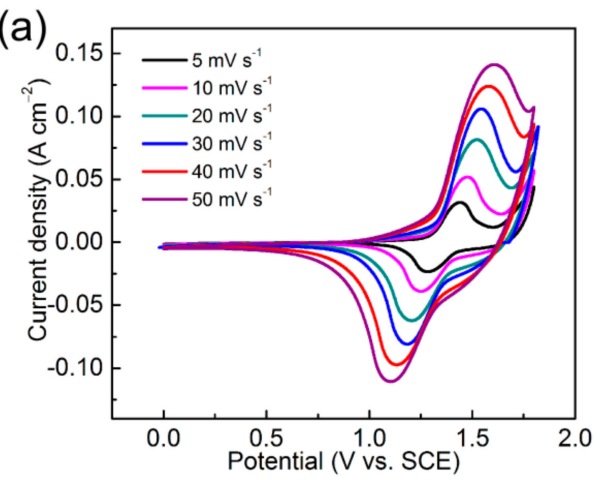

(c)

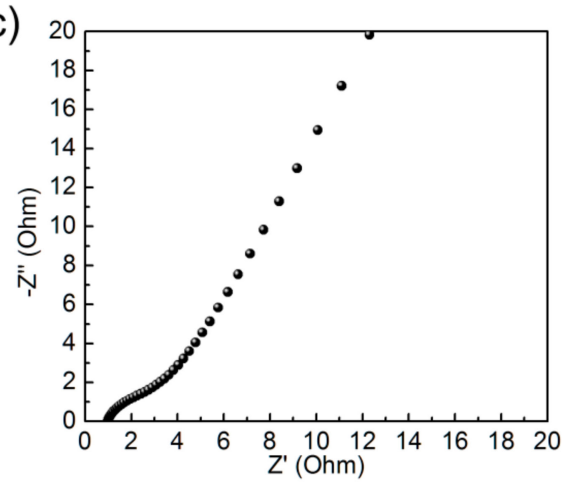

(b)

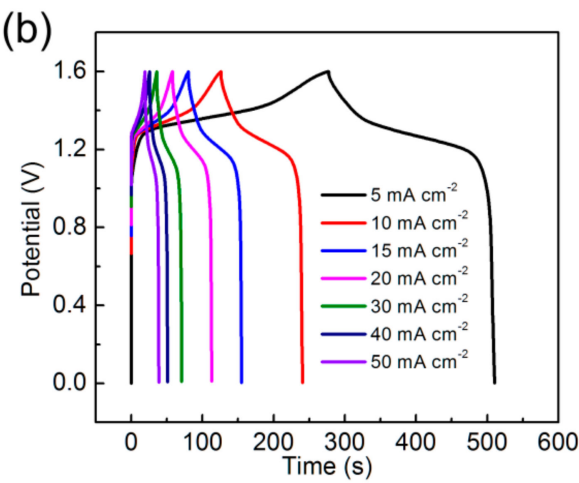

(d)

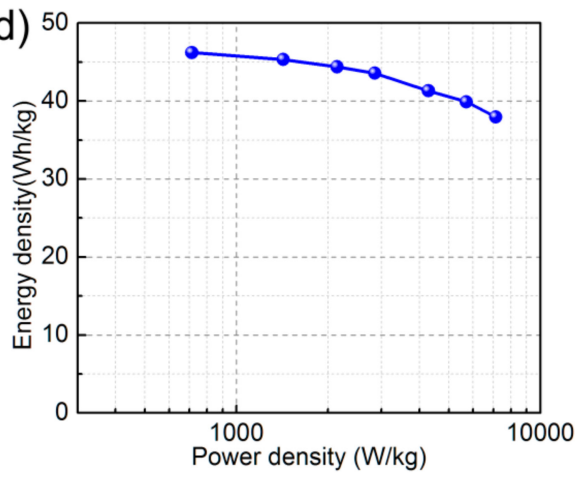

Figure 6. Electrochemical manifestation of the hybrid supercapacitor cell. (a,b) display the CV and GCD curves at different scan rates and current densities, respectively; (c) Nyquist impedance spectrum; (d) Ragone plot.

In addition, we make an electrochemical performance comparison of recent synthesized mixed metal oxide, sulfide, and hydroxide for supercapacitors applications, listed in Table 1. From the comparison, we could conclude that the NCMO nanosheets in this work possess high specific capacitance along with long cycling stability. 
Table 1. Comparison of the electrochemical performance of various mixed metal pseudocapacitor electrodes.

\begin{tabular}{|c|c|c|c|c|}
\hline Electrode Materials & Specific Capacitance & Rate Capability & Cycling Performance & Ref. \\
\hline $\mathrm{Ni}-\mathrm{Zn}$-Co oxide nanowire arrays & $776 \mathrm{Fg}^{-1}$ at $2 \mathrm{~A} \mathrm{~g}^{-1}$ & $73.8 \%$ at $32 \mathrm{~A} \mathrm{~g}^{-1}$ & $\begin{array}{l}88.9 \% \text { of the maximum value } \\
\text { after } 10,000 \text { cycles }\end{array}$ & [29] \\
\hline Ni-Co-Mo oxy-hydroxide nanoflakes & $2562 \mathrm{~F} \mathrm{~g}^{-1}$ at $1 \mathrm{~A} \mathrm{~g}^{-1}$ & $88.4 \%$ at $10 \mathrm{~A} \mathrm{~g}^{-1}$ & $\begin{array}{l}\text { about } 91 \% \text { of its original } \\
\text { capacitance after } 1000 \text { cycles }\end{array}$ & [24] \\
\hline Ni-Co-Mo sulfide nanosheets & $2717 \mathrm{~F} \mathrm{~g}^{-1}$ at $1 \mathrm{~A} \mathrm{~g}^{-1}$ & $83.6 \%$ at $10 \mathrm{~A} \mathrm{~g}^{-1}$ & $\begin{array}{l}\text { about } 80 \% \text { capacitance } \\
\text { retention after } 1000 \text { cycles }\end{array}$ & [25] \\
\hline $\mathrm{Zn}-\mathrm{Ni}$-Co oxides nanowire arrays & $2482 \mathrm{~F} \mathrm{~g}^{-1}$ at $1 \mathrm{~A} \mathrm{~g}^{-1}$ & $91.9 \%$ at $5 \mathrm{~A} \mathrm{~g}^{-1}$ & $\begin{array}{l}94 \% \text { capacitance retention } \\
\text { over } 3000 \text { cycles }\end{array}$ & [26] \\
\hline Mn-Ni-Co oxide nanowire array & $638 \mathrm{~F} \mathrm{~g}^{-1}$ at $1 \mathrm{~A} \mathrm{~g}^{-1}$ & $63.3 \%$ at $20 \mathrm{Ag} \mathrm{g}^{-1}$ & $\begin{array}{l}93.6 \% \text { of the maximum value } \\
\text { after } 6000 \text { cycles }\end{array}$ & [27] \\
\hline $\mathrm{Ni}_{0.8}-\mathrm{Co}_{0.2}$-Se nanowires & $86 \mathrm{Fg}^{-1}$ at $1 \mathrm{~A} \mathrm{~g}^{-1}$ & Not reported & $\begin{array}{l}\text { exceeding } 95 \% \text { over the } \\
2000 \text { cycles test }\end{array}$ & [48] \\
\hline $\mathrm{Ni}_{1 / 3} \mathrm{Co}_{2 / 3} \mathrm{MoO}_{4}$ nanosheets & $1103 \mathrm{~F} \mathrm{~g}^{-1}$ at $1 \mathrm{~A} \mathrm{~g}^{-1}$ & $84.3 \%$ at $10 \mathrm{~A} \mathrm{~g}^{-1}$ & $\begin{array}{l}\text { remaining } 85.18 \% \text { at after } \\
1000 \text { cycles }\end{array}$ & [49] \\
\hline $\begin{array}{l}\text { Hollow Ni-Al-Mn layered hydroxide } \\
\text { nanospheres }\end{array}$ & $1756 \mathrm{~F} \mathrm{~g}^{-1}$ at $4 \mathrm{~A} \mathrm{~g}^{-1}$ & Not reported & $\begin{array}{l}89.5 \% \text { of initial values after } \\
4000 \text { cycles }\end{array}$ & [50] \\
\hline Ni-Co-Mo oxide nanosheet arrays & $1366 \mathrm{~F} \mathrm{~g}^{-1}$ at $2 \mathrm{~A} \mathrm{~g}^{-1}$ & $71.3 \%$ at $40 \mathrm{~A} \mathrm{~g}^{-1}$ & $\begin{array}{l}89.75 \% \text { of the maximum value } \\
\text { after } 5000 \text { cycles }\end{array}$ & This work \\
\hline
\end{tabular}

\section{Conclusions}

We successfully manufactured hierarchical porous NCMO nanosheets on NF by combining a hydrothermal method and an annealing procedure. Due to its nanosheet structure, mesoporous features, and the synergistic enhancement effect, the NCMO nanosheets delivered a high specific capacitance of $1366 \mathrm{~F} \mathrm{~g}^{-1}$ and long cyclability of $89.75 \%$ after 5000 cycles. Additionally, the NCMO nanosheets-based hybrid supercapacitor cell exhibited an energy density of $46.2 \mathrm{Wh} \mathrm{kg}^{-1}$ at $713.0 \mathrm{~W} \mathrm{~kg}^{-1}$. In conclusion, the outstanding electrochemical performance suggests that the as-fabricated NCMO nanosheets could serve as potential electrode materials in practical energy storage applications.

Author Contributions: Conceptualization, W.H.; Formal analysis, Y.S. and W.H.; Investigation, Y.S., D.L. and Z.S.; Methodology, W.H.; Supervision, W.H.; Writing-original draft, Y.S.; Writing-review \& editing, B.T., X.T. and J.Q.

Funding: This research was funded by the Natural Science Foundation of China (No. 51602033), Chongqing Research Program of Basic Research and Frontier Technology (No. cstc2015jcyjBX0038), Fundamental Research Funds for the Central Universities (Nos. 2018CDQYGD0008 and 10611CDJXZ238826), and National Key Research and Development Program of China (Nos. 2016YFE0125200 and 2016YFC0101100).

Conflicts of Interest: The authors declare no conflict of interest.

\section{References}

1. Dunn, B.; Kamath, H.; Tarascon, J.M. Electrical energy storage for the grid: A battery of choices. Science 2011, 334, 928-935. [CrossRef] [PubMed]

2. Simon, P.; Gogotsi, Y.; Dunn, B. Where do batteries end and supercapacitors begin? Science 2014, 343, 1210-1211. [CrossRef] [PubMed]

3. Wang, Y.; Song, Y.; Xia, Y. Electrochemical capacitors: Mechanism, materials, systems, characterization and applications. Chem. Soc. Rev. 2016, 45, 5925-5950. [CrossRef] [PubMed]

4. Qi, D.; Liu, Y.; Liu, Z.; Zhang, L.; Chen, X. Design of architectures and materials in in-plane micro-supercapacitors: Current status and future challenges. Adv. Mater. 2017, 29, 1602802. [CrossRef] [PubMed]

5. Wang, G.; Zhang, L.; Zhang, J. A review of electrode materials for electrochemical supercapacitor. Chem. Soc. Rev. 2012, 41, 797-828. [CrossRef] [PubMed]

6. Yu, Z.; Tetard, L.; Zhai, L.; Thomas, J. Supercapacitor electrode materials: Nanostructures from 0 to 3 dimensions. Energy Environ. Sci. 2014, 8, 702-730. [CrossRef]

7. González, A.; Goikolea, E.; Barrena, J.A.; Mysyk, R. Review on supercapacitors: Technologies and materials. Renew. Sustain. Energy Rev. 2016, 58, 1189-1206. [CrossRef]

8. Yu, M.; Wang, Z.; Han, Y.; Tong, Y.; Lu, X.; Yang, S. Recent progress in the development of anodes for asymmetric supercapacitors. J. Mater. Chem. A 2016, 4, 4634-4658. [CrossRef] 
9. Dong, X.W.; Zhang, Y.Y.; Wang, W.J.; Zhao, R. Rational construction of 3D $\mathrm{NiCo}_{2} \mathrm{O}_{4} @ \mathrm{CoMoO}_{4}$ core/shell nanoarrays as a positive electrode for asymmetric supercapacitor. J. Alloys Compd. 2017, 729, 716-723. [CrossRef]

10. Zhang, L.; Hui, K.N.; Hui, K.S.; Lee, H. High-performance hybrid supercapacitor with 3D hierarchical porous flower-like layered double hydroxide grown on nickel foam as binder-free electrode. J. Power Sources 2016, 318, 76-85. [CrossRef]

11. Yang, Y.; Cheng, D.; Chen, S.; Guan, Y.; Xiong, J. Construction of hierarchical $\mathrm{NiCO}_{2} \mathrm{~S}_{4} @ \mathrm{Ni}(\mathrm{OH})_{2}$ core-shell hybrid nanosheet arrays on $\mathrm{Ni}$ foam for high-performance aqueous hybrid supercapacitors. Electrochim. Acta 2016, 193, 116-127. [CrossRef]

12. Yin, C.; Yang, C.; Jiang, M.; Deng, C.; Yang, L.; Li, J.; Qian, D. A novel and facile one-pot solvothermal synthesis of PEDOT-PSS/Ni-Mn-Co-O hybrid as an advanced supercapacitor electrode material. ACS Appl. Mater. Interfaces 2016, 8, 2741-2752. [CrossRef] [PubMed]

13. Sk, M.M.; Yue, C.Y.; Ghosh, K.; Jena, R.K. Review on advances in porous nanostructured nickel oxides and their composite electrodes for high-performance supercapacitors. J. Power Sources 2016, 308, 121-140. [CrossRef]

14. Guan, C.; Liu, X.; Ren, W.; Li, X.; Cheng, C.; Wang, J. Rational design of metal-organic framework derived hollow $\mathrm{NiCo}_{2} \mathrm{O}_{4}$ arrays for flexible supercapacitor and electrocatalysis. Adv. Energy Mater. 2017, 7, 1602391. [CrossRef]

15. Meher, S.K.; Rao, G.R. Effect of microwave on the nanowire morphology, optical, magnetic, and pseudocapacitance behavior of $\mathrm{Co}_{3} \mathrm{O}_{4}$. J. Phys. Chem. C 2011, 115, 25543-25556. [CrossRef]

16. Raj, S.; Srivastava, S.K.; Kar, P.; Roy, P. Three-dimensional $\mathrm{NiCo}_{2} \mathrm{O}_{4} / \mathrm{NiCo}_{2} \mathrm{~S}_{4}$ hybrid nanostructures on $\mathrm{Ni}$-foam as high-performance supercapacitor electrode. RSC Adv. 2016, 6, 95760-95767. [CrossRef]

17. Hu, W.; Chen, R.; Xie, W.; Zou, L.; Qin, N.; Bao, D. CoNi ${ }_{2} \mathrm{~S}_{4}$ nanosheet arrays supported on nickel foams with ultrahigh capacitance for aqueous asymmetric supercapacitor applications. ACS Appl. Mater. Interfaces 2014, 6, 19318-19326. [CrossRef] [PubMed]

18. Guan, B.Y.; Yu, L.; Wang, X.; Song, S.; Lou, X.W. Formation of onion-like $\mathrm{NiCo}_{2} \mathrm{~S}_{4}$ particles via sequential ion-exchange for hybrid supercapacitors. Adv. Mater. 2017, 29, 1605051. [CrossRef] [PubMed]

19. Wang, H.; Casalongue, H.S.; Liang, Y.; Dai, H. Ni(OH $)_{2}$ nanoplates grown on graphene as advanced electrochemical pseudocapacitor materials. J. Am. Chem. Soc. 2010, 132, 7472-7477. [CrossRef] [PubMed]

20. Liu, Y.; Fu, N.; Zhang, G.; Xu, M.; Lu, W.; Zhou, L.; Huang, H. Design of hierarchical Ni-Co@Ni-Co layered double hydroxide core-shell structured nanotube array for high-performance flexible all-solid-sate battery-type supercapacitors. Adv. Funct. Mater. 2017, 27, 1605307. [CrossRef]

21. Jagadale, A.D.; Guan, G.; Li, X.; Du, X.; Ma, X.; Hao, X.; Abudula, A. Ultrathin nanoflakes of cobalt-manganese layered double hydroxide with high reversibility for asymmetric supercapacitor. J. Power Sources 2016, 306, 526-534. [CrossRef]

22. Cheng, J.; Yan, H.; Lu, Y.; Qiu, K.; Hou, X.; Xu, J.; Han, L.; Liu, X.; Kim, J.; Luo, Y. Mesoporous $\mathrm{CuCo}_{2} \mathrm{O}_{4}$ nanograss as multi-functional electrodes for supercapacitors and electro-catalysts. J. Mater. Chem. A 2015, 3, 9769-9776. [CrossRef]

23. Sahoo, S.; Naik, K.K.; Late, D.J.; Rout, C.S. Electrochemical synthesis of a ternary transition metal sulfide nanosheets on nickel foam and energy storage application. J. Alloys Compd. 2017, 695, 154-161. [CrossRef]

24. Duan, C.; Zhao, J.; Qin, L.; Yang, L.; Zhou, Y. Ternary Ni-Co-Mo oxy-hydroxide nanoflakes grown on carbon cloth for excellent supercapacitor electrodes. Mater. Lett. 2017, 208, 65-68. [CrossRef]

25. Sahoo, S.; Mondal, R.; Late, D.J.; Rout, C.S. Electrodeposited nickel cobalt manganese based mixed sulfide nanosheets for high performance supercapacitor application. Microporous Mesoporous Mater. 2017, 244, 101-108. [CrossRef]

26. Wu, C.; Cai, J.; Zhang, Q.; Zhou, X.; Zhu, Y.; Shen, P.; Zhang, K. Hierarchical mesoporous zinc-nickel-cobalt ternary oxide nanowire arrays on nickel foam as high-performance electrodes for supercapacitors. ACS Appl. Mater. Interfaces 2015, 7, 26512-26521. [CrossRef] [PubMed]

27. Li, L.; Zhang, Y.; Shi, F.; Zhang, Y.; Zhang, J.; Gu, C.; Wang, X.; Tu, J. Spinel manganese-nickel-cobalt ternary oxide nanowire array for high-performance electrochemical capacitor applications. ACS Appl. Mater. Interface 2014, 6, 18040-18047. [CrossRef] [PubMed] 
28. Lee, H.J.; Lee, J.H.; Chung, S.Y.; Choi, J.W. Enhanced pseudocapacitance in multicomponent transition-metal oxides by local distortion of oxygen octahedral. Angew. Chem. Int. Ed. 2016, 55, 3958-3962. [CrossRef] [PubMed]

29. Hu, W.; Wei, H.; She, Y.; Tang, X.; Zhou, M.; Zang, Z.; Du, J.; Gao, C.; Guo, Y.; Bao, D. Flower-like nickel-zinc-cobalt mixed metal oxide nanowire arrays for electrochemical capacitor applications. J. Alloys Compd. 2017, 708, 146-153. [CrossRef]

30. Cai, D.; Liu, B.; Wang, D.; Liu, Y.; Wang, L.; Li, H.; Wang, Y.; Wang, C.; Li, Q.; Wang, T. Facile hydrothermal synthesis of hierarchical ultrathin mesoporous $\mathrm{NiMoO}_{4}$ nanosheets for high performance Supercapacitors. Electrochim. Acta 2014, 115, 358-363. [CrossRef]

31. Singh, A.K.; Sarkar, D.; Khan, G.G.; Mandal, K. Unique hydrogenated Ni-NiO core-shell 1D nano-heterostructures with superior electrochemical performance as supercapacitor. J. Mater. Chem. A 2013, 1, 12759-12767. [CrossRef]

32. Sevilla, M.; Fuertes, A.B. Direct synthesis of highly porous interconnected carbon nanosheets and their application as high-performance supercapacitors. ACS Nano 2014, 8, 5059-5078. [CrossRef] [PubMed]

33. Li, H.; Gao, Y.; Wang, C.; Yang, G. A simple electrochemical route to access amorphous mixed-metal hydroxides for supercapacitor electrode materials. Adv. Energy Mater. 2015, 5, 1401767. [CrossRef]

34. Li, L.; Hui, K.S.; Hui, K.N.; Xia, Q.; Fu, J. Facile synthesis of NiAl layered double hydroxide nanoplates for high-performance asymmetric supercapacitor. J. Alloys Compd. 2017, 721, 803-812. [CrossRef]

35. Hsu, A.R.; Chien, H.H.; Liao, C.Y.; Lee, C.C.; Tsai, J.H.; Hsu, C.C.; Cheng, I.C.; Chen, J.Z. Scan-mode atmospheric-pressure plasma jet processed reduced graphene oxides for quasi-solid-state gel-electrolyte supercapacitors. Coatings 2018, 8, 52. [CrossRef]

36. Zhang, Z.; Liu, Y.; Huang, Z.; Ren, L.; Qi, X.; Wei, X.; Zhong, J. Facile hydrothermal synthesis of $\mathrm{NiMoO}_{4} @ \mathrm{CoMoO}_{4}$ hierarchical nanospheres for supercapacitor applications. Phys. Chem. Chem. Phys. 2015, 17, 20795-20804. [CrossRef] [PubMed]

37. Senthilkumar, B.; Meyrick, D.; Lee, Y.S.; Selvan, R.K. Synthesis and improved electrochemical performances of nano b-NiMoO $4-\mathrm{CoMoO}_{4} \cdot \mathrm{xH}_{2} \mathrm{O}$ composites for asymmetric supercapacitors. RSC Adv. 2013, 3, 16542-16548. [CrossRef]

38. Yin, Z.; Chen, Y.J.; Zhao, Y.; Li, C.; Zhu, C.; Zhang, X. Hierarchical nanosheet-based $\mathrm{CoMoO}_{4}-\mathrm{NiMoO}_{4}$ nanotubes for applications in asymmetric supercapacitor and oxygen evolution reaction. J. Mater. Chem. A 2015, 3, 22750-22758. [CrossRef]

39. Godillot, G.; Taberna, P.L.; Daffos, B.; Simon, P.; Delmas, C.; Guerlou-Demourgues, L. High power density aqueous hybrid supercapacitor combining activated carbon and highly conductive spinel cobalt oxide. J. Power Sources 2016, 331, 277-284. [CrossRef]

40. Li, L.; Cheah, Y.; Ko, Y.; Teh, P.; Wee, G.; Wong, C.; Peng, S.; Srinivasan, M. The facile synthesis of hierarchical porous flower-like $\mathrm{NiCo}_{2} \mathrm{O}_{4}$ with superior lithium storage properties. J. Mater. Chem. A 2013, 1, 10935-10941. [CrossRef]

41. Peng, S.; Li, L.; Wu, H.B.; Srinivasan, M.; Lou, X.W. Controlled growth of $\mathrm{NiMoO}_{4}$ nanosheet and nanorod arrays on various conductive substrates as advanced electrodes for asymmetric supercapacitors. Adv. Energy Mater. 2015, 5, 1401172. [CrossRef]

42. Cai, D.; Wang, D.; Liu, B.; Wang, Y.; Liu, Y.; Wang, L.; Li, H.; Huang, H.; Li, Q.; Wang, T. Comparison of the electrochemical performance of $\mathrm{NiMoO}_{4}$ nanorods and hierarchical nanospheres for supercapacitor applications. ACS Appl. Mater. Interfaces 2013, 5, 12905-12910. [CrossRef] [PubMed]

43. Shen, L.; Che, Q.; Li, H.; Zhang, X. Metal oxides: Mesoporous $\mathrm{NiCo}_{2} \mathrm{O}_{4}$ nanowire arrays grown on carbon textiles as binder-free flexible electrodes for energy storage. Adv. Funct. Mater. 2014, 24, 2630-2637. [CrossRef]

44. Veerasubramani, G.K.; Krishnamoorthy, K.; Sang, J.K. Improved electrochemical performances of binder-free $\mathrm{CoMoO}_{4}$ nanoplate arrays@Ni foam electrode using redox additive electrolyte. J. Power Sources 2016, 306, 378-386. [CrossRef]

45. Ding, R.; Qi, L.; Jia, M.; Wang, H. Facile synthesis of mesoporous spinel $\mathrm{NiCo}_{2} \mathrm{O}_{4}$ nanostructures as highly efficient electrocatalysts for urea electro-oxidation. Nanoscale 2013, 6, 1369-1376. [CrossRef] [PubMed]

46. Ghosh, K.; Yue, C.Y. Development of $3 \mathrm{D} \mathrm{MoO}_{3}$ /graphene aerogel and sandwich-type polyaniline decorated porous $\mathrm{MnO}_{2}$-graphene hybrid film based high performance all-solid-state asymmetric supercapacitors. Electrochim. Acta 2018, 276, 47-63. [CrossRef] 
47. Riley, L.A.; Lee, S.H.; Gedvilias, L.; Dillon, A.C. Optimization of $\mathrm{MoO}_{3}$ nanoparticles as negative-electrode material in high-energy lithium ion batteries. J. Power Sources 2010, 195, 588-592. [CrossRef]

48. Guo, K.; Cui, S.; Hou, H.; Chen, W.; Mi, L. Hierarchical ternary Ni-Co-Se nanowires for high-performance supercapacitor device design. Dalton Trans. 2016, 45, 19358-19465. [CrossRef] [PubMed]

49. Zhang, J.; Zhang, R.; Song, P.; Zhao, J.; Guo, X.; Zhang, D.; Yuan, B. CoMoO 4 and $\mathrm{Ni}_{1 / 3} \mathrm{Co}_{2 / 3} \mathrm{MoO}_{4}$ nanosheets with high performance supercapacitor and nonenzymatic glucose detection properties. RSC Adv. 2015, 5, 84451-84456. [CrossRef]

50. Chandrasekaran, N.I.; Muthukumar, H.; Sekar, A.D.; Manickam, M. Hollow nickel-aluminium-manganese layered triple hydroxide nanospheres with tunable architecture for supercapacitor application. Mater. Chem. Phys. 2017, 195, 247-258. [CrossRef]

(c) 2018 by the authors. Licensee MDPI, Basel, Switzerland. This article is an open access article distributed under the terms and conditions of the Creative Commons Attribution (CC BY) license (http:/ / creativecommons.org/licenses/by/4.0/). 